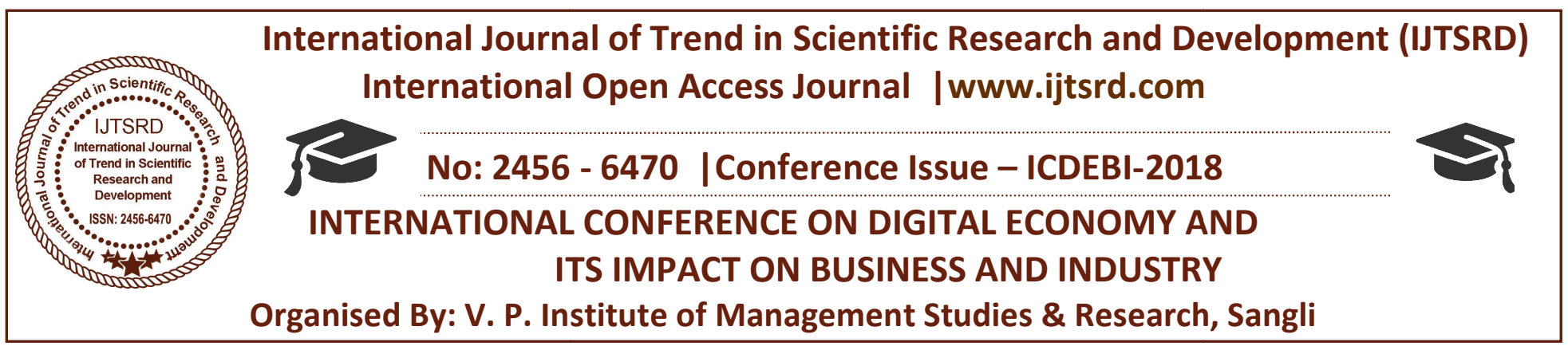

\title{
Digitalization in Marketing
}

\author{
Mallikarjun Raju Chikkodi \\ M.Com Student, K.L.E. Society's B. K. College of Commerce, \\ Chikkodi, Belagavi, Karnataka, India
}

\begin{abstract}
In this seminar I would like to show about the digitalization in marketing and its performing in our day to day life such as its needs, types and its advantages and also its disadvantages. Digitalization in marketing is playing a very important role in the
\end{abstract} economy.

\section{NEEDS OF DIGITALIZATION IN \\ MARKETING: \\ Every business will have different specific goal in} mind, but almost all are trying to reach more customers and convince them to purchase to do thus effectively, you have to take benefit of all the most precious marketing resources and technologies. Which include:

\section{Affordability}

Digital marketing is noticeably low expensive than other marketing techniques. Specific prices vary based on what you're doing but ad spend tends to be lower than other forms of marketing.

2. Mobile admittance

You may not know thus but 77 percent of American youths are on a smart phone and are likely o use that smart phone or another mobile device for news, social networking, and countless other actions .Digital marketing lets you reach them while they're doing this.

\section{Flexibility}

There are many forms and benefits of digital marketing. Including banner ads, email marketing, content marketing, and social media posts. Thus by learning how to market yourself digitally, you open up a wide range of possibilities for future publicity strategy.

\section{4. extension}

Many customers do almost all of their shopping online. Digital marketing lets you to request to these people and thus develop the reach of your business.

5. Multimedia: Consumers tend in the direction of more with marketing materials that mingle numerous types of content, including photos, video clips, and audio. It is far easier to incorporate all these content types into digital marketing than any other type of publicity -and it is very important.

6. Interactivity:

Digital marketing lets you be in touch directly with the consumers who perceive you content, notably through website comments, messages, reviews, and social media posts. This shows those consumers that you care about what they say and think, leading them to think respected and Part of the society you're building.

7. Tracking:

Besides communicating with consumers digital marketing lets you track their activities. You can keep an eye on which ads and types of content they have seen shortly before they make a buy.

\section{Types of digital marketing}

\section{Social Media Marketing}

The social Ms has a muscular focus on social media marketing. So that is where we are going to start our list of types of digital marketing. Social Media positively has fairly earned position in the record. Social media marketing is, the use of social media platforms and websites to support a goods or service. 


\section{Content Marketing}

Content marketing is the ability of using storytelling and important information to raise brand knowledge with the objective of getting your target viewers to take a gainful action. Content marketing aims at building interaction with probable consumers and becoming a colleague rather than an advertiser. Content marketing strongly relies on content delivery. Content marketing can hardly ever be seen completely divided from other types of digital marketing that can fill the content distribution part.

3. Search Engine Optimization (SEO)

SEO is the course of action of optimizing content or websites so that they explain up in explore outcome in search engines such as Google. Search engines settle on which websites to prove for a search term based on keywords mentioned on the website and links that pass on to this website. That means SEO has a lot to do with using the right keywords or key phrases in the copy of a website or within the content.

4. Search Engine Marketing (SEM):

While SEO describes the course of action of perceiving not paid traffic from search engines SEM refers to the paid traffic from search engines. The most general form of search engine marketing is probably Google $\mathrm{Ad}$ words for the uncomplicated cause that Google is by far the most used search engine.

5. Pay-Per-Click Advertising (PPC): Similar to SEM other forms of PPC advertising also illustrate marketing techniques where the marketer pays for each click on a link.

\section{Advantages or benefits of Digital Marketing:}

1. Level playing field:

Any company can challenge with any enemy apart from of element with a well-built digital internet marketing approach. Furthermore, typically a minor store would find it difficult to bring together the grace of the accessories of its larger opponents. Online, a sharp well thought out site with a sleek consumer trip and incredible service is master - not dimension.

\section{Low cost:}

It allows to companies to save money, an component that is really taken into account by the companies since the Digital marketing strategies don't necessitate a great amount of financial commitment.

\section{Easy to measure:}

Online everything can be calculated, thus it's simpler for the companies to know right away if their strategy is operating or not, what business concern or customer is enthusiastic about their items, from what places or nations are they, etc.

\section{Brand growth:}

Continuation on the Internet can help the development of the business organization from any local market to country wide and worldwide market locations at the same time, providing almost boundless development opportunities.

\section{Available 24/7:}

The World Wide Web not at all rests and so does Online promotion, enabling company with small sources to maintain physical 24-hour functions to contend in the electronic industry using Online promotion resources that can run almost 24 hours a day and 7 days a week.

\section{Dis-advantages of Digital Marketing:}

1. Promotion policy canbecopied:

One of the hazards in Internet marketing is that a particular method can easily be copied by a rival. And, many have done so with conclude ignore for the lawful repercussions their actions may bring. Pictures or images can be used to mislead consumers and bring away an important company. From you. Not only that, these can also be used for perpetrating adverse and incorrect information about your goods, products or services that will dangerous your online reputation - and minimize useful focused consumers.

\section{Digital Marketing Includes Too Much} Competition:

Just like the development of online ads, Internet promotion is knowledgeable with a great process of too many competitors. Digital promoters are not competent of receiving into a more powerful place for the best possible disclosure for their promotion and promotion tasks, and with the use of too many competitors, will make it even more difficult and costly to get the interest of targeted observers.

\section{Security problem:}

Internet marketing has its own demerits which are not noticeable on its knowledge value. so, For a person or client who queries online for goods or services, there is a caution not to disclose all the private information as it might be used against them by nameless people. 


\section{4. lack of belief:}

One of the important disadvantages may be a absence of believing in of the customers. Because of could be exclusive extraordinary offers that come out to be scammers. So, this is a part that reduces the image and reliability of quality and sincere business organization.

5. Requires More primary Investment:

Playing Digital marketing contains various boundaries like developing delicate and professional looking for your website and planning an effective system. Therefore, Paid marketing like Search engines Ad Words, Search engines Ads, and Social Media Marketing is quite expensive, especially for small enterprise owners.

\section{Conclusion:}

So, digitalization in marketing is about utilising digital technology to reach marketing goals. There is no essential necessitate for digital marketing to always be separate from the mark technology department as a whole, as the goals of both are the same. However, for now, it remains a useful term because digital marketing needs a certain skill set to utilise the digitalogy effectively. 